\section{Global Student and Talent Flows: Reexamining the Brain Drain Equation}

\author{
RAJIKA BHANDARI
}

Rajika Bhandari is senior advisor, research and strategy, and director, IIE Center for Academic Mobility Research and Impact, Institute of International Education (IIE), US. E-mail: rajika_bhandari@yahoo. com.

$\mathrm{T}$ he global movement of postsecondary students remains a remarkably unidirectional phenomenon: students from the developing world, or Global South, take their knowledge and talent to the developed world, or Global North. Eight of the top io host countries are all located in the developed world and attract approximately 60 percent of the world's five million mobile students. As sending countries, China and India alone account for a quarter of the world's mobile students. At the same time, the rise of new and nontraditional destinations (e.g., China); intraregional mobility; and the growth of South-South mobility cannot be ignored.

Despite these newer developments, outbound mobility from both China and India remains high, numerically and in terms of quality: in 2017, 869,387 students from China and 306,000 from India were studying abroad. While these large absolute numbers represent a very small proportion of the college-age cohort in both countries-I percent for China and 0.3 percent for India-these low proportions mask the human capital potential and "quality" of the students that leave to go abroad. Quality can be subjective, but one proxy is to examine what Indian and Chinese students are studying overseas, with higher levels of education and certain fields of study associated with greater gains for receiving countries and economies. In the United States, for example, almost half of all Indian students are enrolled at the graduate level and in the STEM fields (8I percent). As for Chinese students in the United States, while undergraduates now outnumber graduate students, 36 percent are nevertheless pursuing master's and doctoral degrees.

\section{Revisiting the Brain Drain Issue}

In the I950s and I960s, the issue of "brain drain" was front and center and was even described as a form of neocolonialism. By the twenty-first century, the discourse had shifted to "brain circulation" or even "brain gain." It was widely argued that the loss of human capital by sending countries had been replaced by a balanced exchange of knowledge; long-term international partnerships between equal play- ers; and high economic contributions of emigrants to their home countries in the form of remittances. Yet current estimates of immigrant and emigrant populations show that most immigrants are heavily clustered in the developed world, while emigrants come mainly from developing countries in Asia, Africa, and Latin America. Evidence on "stay rates" and "return rates" suggests that a very large proportion of students from developing countries continue to immigrate to their host country, and regions like Africa continue to experience a significant loss of human capital through student mobility. In 20I7, in the United States alone, almost 90 percent of Indian doctoral students and 83 percent of Chinese doctoral students indicated their interest in remaining in the United States after their studies. Additionally, 80 percent of international doctorate recipients in STEM fields with definite postgraduation plans reported that their future employment was in the United States.

\section{What Sending and Receiving Countries Can Do}

Solutions for balancing the knowledge equation between sending and receiving countries require an understanding that the fundamental motivations of international students from the developing world are different from those from developed countries. Take the case of Indian students: their primary motivations for studying in the West are not the pursuit of cultural exchange or the desire to learn a foreign language. Rather, their considerations are more pragmatic, driven by the insufficient capacity of high-quality Indian

\section{The field of student mobility today is go- ing through a period of reflection and stocktaking, primarily due to an altered political and social landscape.}

institutions and their desire for professional advancement. This fits within both the "constrained-schooling" and the "migration-for-employment" hypotheses. On the other hand, student flows between developed countries-such as between Europe and the United States-are often pursued for reasons such as mutual and cultural exchange, science diplomacy, and the overall Western philosophy of broadening one's perspectives.

Acknowledging the students' motivations, sending and receiving countries can play a role in mitigating the current imbalance, both at the policy and at the institutional levels. Ziguras and Gribble offer a three-part framework for home or sending countries: retention, return, and engagement. Retention approaches aim to provide sufficient and 
high-quality higher education locally, to prevent high levels of student migration in the first place. This is the sort of recent expansion and capacity building seen in both China and India. Second, countries are also offering incentives for their foreign-educated talent to return home; one analysis suggests that there are at least I8 countries with programs designed to attract expatriates. The third group of engagement and network strategies is based on the recognition that highly educated and qualified individuals settled overseas can be engaged through diaspora networks and other initiatives that may ultimately benefit their home country and allow them to contribute, albeit from a distance.

What can receiving countries do? First, at the national level, scholarships offered by host countries are an enduring mechanism to increase access not only for students from poorer countries, but also for marginalized and underrepresented students within those countries-such scholarships are now being monitored through target 4.b of the Sustainable Development Goals (SDGs). Second, institutions should not only diversify the countries from which they recruit international students, but should also pay more attention to how they can increase access for potential international students who might not have the means or know-how to access a global education opportunity. Finally, more can be done at the institutional and national levels in major destination countries, to foster international networks and collaborations that enable their international students and immigrant/diaspora faculty to connect with their peers in their home countries.

The field of student mobility today is going through a period of reflection and stocktaking, primarily due to an altered political and social landscape. It is therefore timely to revisit and examine the fundamental ethics, assumptions, and power dynamics that underpin student mobility: how do we ensure that the mobility of students and talent is based on principles of access, equity, and inclusiveness, both at the student level and at the national level? The SDGs have also brought a renewed focus to these issues. Lastly, there are some key gaps in data and knowledge that also need to be addressed. Not enough is known about the socioeconomic background of students who participate in a mobility experience. More concrete measurements are needed of which type of students leave their countries and how this impacts the future talent pools of both home and host countries. And given that there will always be larger outflows of students and talent from the Global South, we need to develop more meaningful and nuanced measures of how skilled immigrants and diaspora communities continue to contribute to their home countries through fostering international collaborations and networks-multiplier effects that go beyond simplistic (albeit critical) financial measures such as remittances.

\section{Rankings and the Public Good Role of Higher Education}

\section{Ellen Hazelkorn}

Ellen Hazelkorn is professor emerita and director, Higher Education Policy Research Unit, Dublin Institute of Technology, Ireland, and partner, BH Associates, Education Consultants. E-mail: ellen.hazelkorn@ dit.ie.

$\mathrm{O}$ ne of the most prominent issues of public and political concern today is the extent to which universities contribute to the public good. Universities have historically had a close relationship with the city and country of their founding. Yet, today, they are often considered part of the elite. Student learning and graduate outcomes are often discounted in preference to pursuing global reputation.

Unequal distribution of societal goods has spurred a deep sense of grievance as evidenced by recent elections and political turmoil around the world. The recent scandal in the United States about financial payments to enable back-door entry to elite universities highlights intensifying social stratification while also raising fundamental questions about the role and responsibilities of universities. These issues are framing the background around increased attention and monitoring of universities. This has placed them under pressure to contribute more to their communities and regions, work with business and civil society, and demonstrate how well they do this.

Rankings have portrayed themselves as promoting greater public information and disclosure, comparing performance internationally to inform students/parents, governments, and the wider public. But too often, rankings measure benefits gained from accumulated public and/or private wealth and investment over decades if not centuries. Their choice of indicators cherish the benefits of attracting high achieving/high socioeconomic students who graduate on time and go on to have successful careers. Excellence is measured in terms of achievements of individual universities rather than public good to society collectively. These factors are reproduced in the indicators that rankings use and popularize. 